\title{
DDT (DICLORO DIFENIL TRICLOROETANO): TOXICIDADE E CONTAMINAÇÃO AMBIENTAL - UMA REVISÃO
}

\author{
Claudio D’Amato, João P. M. Torres* e Olaf Malm
}

Instituto de Biofísica Carlos Chagas Filho, Universidade Federal do Rio de Janeiro, Centro de Ciências da Saúde, 21949-900

Rio de Janeiro - RJ

Recebido 27/9/01; aceito em 19/3/02

\begin{abstract}
DDT (DICHLORODIPHENYLTRICHLOROETHANE): TOXICITY AND ENVIRONMENTAL CONTAMNATION - A REVIEW. DDT and others organochlorine insecticides are very persistent substances. Clinical symptoms of intoxication have been reported in humans, although the main problem concerning such substances is bioaccumulation and biomagnification along throphic chains, leading to contamination of top predators and humans after them. In this review these characteristics are described, as well as some aspects of the control of vector borne diseases, like leishmaniasis and malaria, which were until recently, controlled by the health authorities using DDT.
\end{abstract}

Keywords: DDT; environment; fish.

\section{INTRODUÇÃO}

O diclorodifeniltricloroetano (DDT) é o mais conhecido dentre os inseticidas do grupo dos organoclorados. Estes pesticidas incluem os derivados clorados do difenil etano (onde se inclui o DDT, seus metabólitos DDE e DDD, e o metoxicloro); o hexaclorobenzeno (BHC); o grupo dos hexaclorocicloexanos $(\alpha-\mathrm{HCH}, \beta-\mathrm{HCH}, \delta-\mathrm{HCH}$ e $\gamma$-HCH ou lindano); o grupo dos ciclodienos (aldrin, dieldrin, endrin, clordano, nonaclor, heptaclor e heptaclor-epóxido), e os hidrocarbonetos clorados (dodecacloro, toxafeno, e clordecone) $)^{1,2}$.

O DDT é considerado uma das substâncias sintéticas mais utilizadas e estudadas no século XX.

\section{HISTÓRICO}

As propriedades inseticidas do DDT foram descobertas em 1939 pelo entomologista suíço Paul Müller, o que lhe valeu posteriormente o Prêmio Nobel da Medicina devido ao uso do DDT no combate à malária ${ }^{3}$.

O DDT foi utilizado na Segunda Guerra Mundial para prevenção de tifo em soldados, que o utilizavam na pele para combate a piolhos. Posteriormente foi usado na agropecuária, no Brasil e no mundo, dado seu baixo preço e elevada eficiência ${ }^{4}$.

A produção em grande escala iniciou-se em 1945, e foi muito utilizado na agricultura como pesticida, por cerca de 25 a 30 anos. Tanta foi a quantidade que se estimou que cada cidadão norte-americano ingeriu, através dos alimentos, uma média de $0,28 \mathrm{mg}$ por dia em $1950^{5}$. Outra função para seu uso foi em programas de controle de doenças tropicais, inclusive no Brasil, como malária e leishmaniose visceral ${ }^{6}$.

Foi a descoberta do DDT que revolucionou os conceitos de luta contra a malária. Sua eficácia contra formas adultas dos mosquitos e seu prolongado efeito residual fizeram com que no período de 19461970 todos os programas de controle se apoiassem quase que totalmente em seu emprego ${ }^{7}$

Em 1962, Rachel Carson sugeriu em seu livro "Primavera Silenciosa", que o amplo uso do DDT poderia ser a principal causa da redução populacional de diversas aves; muitas delas seriam as de

*e-mail: jptorres@biof.ufrj.br topo de cadeia alimentar, como o falcão peregrino, e a águia calva ("bald eagle"- Haliaeetus leucocephalus), animal símbolo dos EUA. Este livro é considerado a primeira manifestação ecológica contra o uso indiscriminado do DDT ${ }^{8}$.

Nos EUA, o uso cresceu, chegando a até 35.771 toneladas produzidas em 1959, principalmente para exportação, chegando a 81.154 toneladas em 1963. Então a produção começou a declinar, sendo que a quantidade produzida para uso no país em 1969 não passou de 13.724 toneladas; entretanto, continuou sendo fabricado em outros países, sendo sua produção mundial, em 1974, de 60.000 toneladas ${ }^{3}$.

A Suécia foi o primeiro país do mundo a banir o DDT e outros inseticidas organoclorados, em $1^{\circ}$ de janeiro de 1970 , com base em estudos ecológicos. Pouco depois foi seguida por outros países, excetuando-se o uso em programas de controle de doenças ${ }^{3}$.

No Brasil, as primeiras medidas restritivas se deram em $1971^{9}$, com a Portaria n. ${ }^{\circ}$ 356/71, que proibiu a fabricação e comercialização de DDT e BHC para combate de ectoparasitos em animais domésticos no país, obrigando os fabricantes a recolherem os produtos, mas isentou os produtos comerciais indicados como larvicidas e repelentes de uso tópico; e com a Portaria $\mathrm{n}^{\mathrm{o}} 357 / 71^{10}$, que proibiu em todo o território nacional o uso de inseticidas organoclorados em controle de pragas em pastagens.

Estes atos fundamentaram-se:

- na formação de resíduos tóxicos na carne e no leite de animais domésticos;

- sua acumulação após tratamentos repetidos;

- no prejuízo que a ocorrência destes resíduos acarretava às exportações de produtos de origem animal devido a medidas restritivas impostas por países importadores;

- e nas recomendações da FAO e OMS para que o uso de DDT e BHC fosse substituído por outros produtos.

Em 1985 proibiu-se em todo o território nacional a comercialização, o uso e a distribuição de produtos organoclorados destinados à agropecuária. Mas os inseticidas organoclorados continuaram sendo permitidos em campanhas de saúde pública no combate a vetores de agentes etiológicos de moléstias (malária e leishmaniose), bem como em uso emergencial na agricultura, a critério do Ministério da Agricultura. Também manteve-se a permissão do uso de iscas formicidas à base de aldrin e dodecacloro, e do uso de cupinicidas à base de aldrin para reflorestamento ${ }^{11}$. 
No Brasil, seu uso em saúde pública ficou sob responsabilidade da Fundação Nacional de Saúde (atual FUNASA), em seu Programa Nacional de Controle de Vetores. A última compra efetuada pelo órgão foi um lote de 3 mil toneladas em 1991, para o controle de Anopheles darlingi na Amazônia ${ }^{6}$.

Em 1995, foi publicado pela OMS um informe técnico declarando que o DDT pode continuar sendo utilizado no controle dos mosquitos vetores de malária e outras doenças transmitidas por artrópodes, desde que se cumpram as seguintes condições:

- seja empregado unicamente em interiores;

- seja eficaz;

- sejam adotadas as regras de segurança necessárias;

- sejam levados em conta o custo do produto a ser utilizado; a disponibilidade de inseticidas alternativos e a possibilidade do aparecimento de insetos resistentes ${ }^{12}$.

Historicamente, a América do Sul é considerado o continente em que houve o mais pesado uso de DDT, além de toxafeno e lindano ${ }^{13}$.

\section{PROPRIEDADES FÍSICO-QUÍMICAS}

O termo DDT refere-se ao produto 1,1'-(2,2,2-tricloroetilideno) bis[4-clorobenzeno]), ou 1,1,1-tricloro-2,2-bis-(p-clorofenil) etano ${ }^{14}$. O termo também é aplicado a produtos comerciais constituídos principalmente pelo isômero $p$, $p$ '- DDT, com proporções menores de outros análogos. O inseticida DDT é constituído, em geral, pela seguinte formulação: $p, p$ '- DDT $(77,1 \%), o, p$ '- DDT $(14,9 \%), p, p$ '$\operatorname{DDD}(0,3 \%), o, p$ '- DDD $(0,1 \%)$ e impurezas $(3,5 \%)$. Todos os isômeros são substâncias sólidas, brancas, inodoras e insípidas, com a fórmula empírica $\mathrm{C}_{14} \mathrm{H}_{9} \mathrm{Cl}_{5}{ }^{15}$.

O ponto de fusão do $p, p$ '- DDT é $109^{\circ} \mathrm{C}$, com pressão de vapor $2,53 \times 10^{-5} \mathrm{~Pa}\left(1,9 \times 10^{-7} \mathrm{mmHg}\right)$ a $20^{\circ} \mathrm{C}^{15}$. Possui hidrossolubilidade bastante baixa, na ordem de $1 \mu \mathrm{g} / \mathrm{L}$, tendo porém elevada lipossolubilidade, com coeficiente de partição octanol/água $\left(\mathrm{K}_{\mathrm{ow}}\right)$ igual a 9,6 x 10 $0^{516}$. A solubilidade em solventes orgânicos encontrase na seguinte proporção $(\mathrm{g} / 100 \mathrm{~mL})$ : benzeno $(106)$, ciclohexanona (100), clorofórmio (96), éter de petróleo (10), etanol $(1,5)^{15}$.

Ao perder uma molécula de $\mathrm{HCl}$, por degradação biológica ou ambiental, o p.p'-DDT forma o metabólito 2,2-bis-p-clorofenil-1,1dicloroetileno, conhecido como DDE. Este composto é ainda mais resistente às degradações que o DDT. Outro metabólito importante formado é o DDD, 2,2-bis-p-clorofenil-1,1-dicloroetano. Há ainda outros: DDMU, DDMS, DDNU, DDOH e DDA ${ }^{3}$. Este último metabólito é o único que não é lipossolúvel, sendo eliminado pela urina dos seres vivos. O DDE, por ser o mais persistente em organismos vivos, pode servir como indicador de exposição dos seres vivos ao DDT como, por exemplo, peixes de um rio contaminado ${ }^{17}$.

\section{TOXICIDADE DO DDT}

Embora o DDT atravesse facilmente o exoesqueleto quitinoso dos insetos, ele é pouco absorvido pela pele humana, o que explica sua relativa baixa toxicidade a nível tópico. $\mathrm{O}$ ser humano pode ser contaminado por exposição direta (inalação) ou por alimentos contaminados com DDT e outros pesticidas organoclorados. Sendo lipossolúveis, possuem apreciável absorção tecidual. São facilmente absorvidos pelas vias digestiva e respiratória. Devido à grande lipossolubilidade e à lenta metabolização, os organoclorados acumulam-se na cadeia alimentar e no tecido adiposo ${ }^{18}$.

Os pesticidas organoclorados, entre os quais inclui-se o DDT, atuam sobre o sistema nervoso central, resultando em alterações de comportamento, distúrbios sensoriais, do equilíbrio, da atividade da musculatura involuntária e depressão dos centros vitais, particularmente da respiração ${ }^{18}$.
Os efeitos do DDT no organismo ocorrem depois de atuarem sobre o equilíbrio de sódio/potássio nas membranas dos axônios, provocando impulsos nervosos constantes, que levam à contração muscular, convulsões, paralisia e morte. A intoxicação aguda nos seres humanos caracteriza-se por cloracnes, na pele, e por sintomas inespecíficos, como dor de cabeça, tonturas, convulsões, insuficiência respiratória e até morte, dependendo da dose e do tempo de exposição ${ }^{3}$.

Em casos de intoxicação aguda, após 2 h surgem os sintomas neurológicos de hiperexcitabilidade, parestesia na língua, lábios e membros inferiores, desconforto, desorientação, fotofobia, cefaléias persistentes, fraqueza, vertigem, alterações de equilíbrio, tremores, ataxia, convulsões tônico - clônicas, depressão central severa, coma e morte ${ }^{18}$

Os sintomas específicos podem ocorrer em caso de inalação ou absorção respiratória, como tosse, rouquidão, edema pulmonar, irritação laringotraqueal, rinorréia, bradipnéia, hipertensão e broncopneumonia (esta última uma complicação freqüente $)^{18}$.

Os pacientes atendidos no Centro de Controle de Intoxicações (CCI) do Hospital Universitário da UNICAMP, no período de janeiro de 1984 a junho de 1985 , devido a intoxicações por inseticidas, atingiram $30 \%$ do total, equivalendo a 592 casos. Dentro deste grupo, 141 casos $(23,8 \%)$ eram por pesticidas organoclorados ${ }^{19}$. Isto ocorreu antes da proibição da comercialização e uso de inseticidas organoclorados pelo Governo Federal ${ }^{11}$.

As manifestações crônicas consistem em neuropatias periféricas, incluindo paralisias, discrasias sangüíneas diversas que podem até ser consequências de aplasia medular, lesões hepáticas com alteração das enzimas transaminases e fosfatase alcalina, lesões renais e $\operatorname{arritmias}^{18}$.

Foi verificado em camundongos uma incidência aumentada de tumores hepáticos, após uma exposição a altas doses, por longo prazo. Embora não tenha se verificado o mesmo com outros animais como ratos, cães, hamsters ou macacos ${ }^{20}$. O DDT é um promotor de tumores, isto é, ele não causa os efeitos genéticos que culminam com o surgimento das neoplasias, mas potencializa a divisão das células neoplásicas que já tenham surgido. Também foi demonstrada, a nível celular, inibição das comunicações intercelulares em forma de placa, denominadas junções "gap", presentes na membrana das células normais ${ }^{20}$. Estas junções não se encontram em células tumorais. Ao perdê-las, as células não são mais inibidas em sua divisão ao entrar em contato com outros tecidos, replicando-se então indefinidamente ${ }^{21}$.

Em um estudo sobre a associação da presença do metabólito DDE no tecido adiposo de pacientes com 6 tipos de câncer (fígado, pâncreas, seio, útero, mieloma múltiplo e linfoma não Hodgkin), os resultados encontrados por Cocco et al. ${ }^{22}$ não indicaram correlação para a maioria deles. Mas, embora não se tenha encontrado correlação positiva entre câncer hepático e DDT, em pessoas negras esta correlação apareceu no segmento formado por indivíduos brancos. Com base neste achado e na já conhecida associação entre câncer hepático e DDT em camundongos, os autores afirmam que novos estudos devam ser feitos sobre o assunto, a fim de confirmar ou rejeitar a hipótese de associação.

DDT é também um potente indutor das enzimas hepáticas do citocromo $\mathrm{P} 450$, que promovem a ativação de outras substâncias carcinogênicas, como a Aflatoxina $\mathrm{B}_{1}$ e a ciclofosfamida. A presença de DDT potencializa, portanto, os efeitos destes carcinógenos ${ }^{20}$.

A eliminação se dá pela urina, cabendo destacar também a importante via de eliminação pelo leite materno ${ }^{18}$, colocando em exposição elevada bebês lactentes. Vannuchi ${ }^{23}$ observou em Londrina, em 1984, uma contaminação de leite materno de $0,142 \mathrm{mg} / \mathrm{kg}$ de $p, p^{\prime}-$ $\mathrm{DDT}+p, p$ '- DDE, indicando que os bebês estavam ingerindo uma concentração maior que o estipulado posteriormente pelo Codex 
Alimentarius $^{24}$, para leite de vaca $(0,05 \mathrm{mg} / \mathrm{kg}[\mathrm{ppm}]) . \mathrm{O}$ que indica que a situação destas crianças era crítica.

Beretta e Dick ${ }^{25}$, em um levantamento realizado em mulheres lactantes da zona urbana de Porto Alegre, Rio Grande do Sul, entre 1987 e 1988, encontraram valores médios de 2,98 ppm ( $\mu \mathrm{g} / \mathrm{g}$ de gordura do leite), de $\Sigma$ DDT (DDT + DDE + DDD) variando entre 0,32 e 12,4 ppm. Das amostras analisadas, $73 \%$ excediam o limite de 1,25 ppm. E dentre os constituintes de $\sum$ DDT, $p, p$ '- DDE chegava à proporção de $95 \%$, com uma concentração média de $2,53 \mathrm{ppm}$. Segundo as autoras, a lei federal promulgada em $1985^{11}$ não estava sendo obedecida.

\section{Efeito hormonal}

O metabólito DDD foi, além de inseticida, utilizado como droga no controle da produção de corticóides pela glândula adrenal ${ }^{3}$.

Acreditava-se que o DDT e seus outros metabólitos não possuíam efeitos endócrinos, mas no final dos anos 80 os estudos de Bryan et al. ${ }^{26}$ sugeriram que o DDT era um mimetizador de estrógenos, isto é, possuía propriedades farmacológicas semelhantes, e então começou-se a verificar o efeito hormonal da exposição ao DDT e seus derivados.

Estes compostos realmente podem atuar semelhantemente a hormônios como o estrogênio, ao ligarem-se a receptores específicos e induzirem efeitos estrogênicos. Os hidrocarbonetos clorados, especialmente o $o, p^{\prime}$ - DDT exercem estes efeitos em répteis, aves e mamíferos. A possibilidade que eles tenham um efeito complexo, ao interagir com diferentes receptores de hormônios esteróides, em diferentes níveis, com consequiências bioquímicas e fisiológicas ainda desconhecidas, precisa ser verificada ${ }^{27}$.

Em mamíferos, um dos efeitos estrogênicos induzidos pelo $o, p$ 'DDT é o aumento do peso uterino em fêmeas. Nos machos, também bloqueia os receptores andrógenos. Já o metabólito $p$, $p$ - DDE possui pouca capacidade de se ligar ao receptor estrógeno, mas inibe a ligação entre o receptor andrógeno e a testosterona. Seus efeitos em experimentos com ratos de laboratório causaram manutenção de mamilos torácicos, atraso na separação do prepúcio no pênis e diminuição da vesícula seminal e próstata ${ }^{28}$.

Hayes et $a l .{ }^{29}$, em estudo com o anfíbio africano Kassina senegalensis, chegaram a resultados sugestivos de que o DDT mimetiza corticosterona ou atua como agente estressante, causando um aumento da corticosterona endógena.

Beard et $a l .{ }^{30}$ examinaram a relação entre os níveis plasmáticos de DDE e densidade mineral óssea em 68 mulheres, sedentárias, que declararam ter aporte nutricional adequado de cálcio, e encontraram resultados sugestivos de que exposições a DDT podem estar associadas à redução da densidade mineral óssea.

Romieu et al. ${ }^{31}$ analisaram a relação entre histórico de lactação, níveis plasmáticos de DDT e DDE e risco de câncer de mama, em um estudo conduzido entre mulheres residentes da Cidade do México, entre 1990 e 1995. A quantidade de DDT no soro não foi associado a risco de câncer, mas a presença de níveis altos de DDE, principalmente entre mulheres pós-menopausa, pode aumentar os riscos de câncer de mama.

\section{CONTAMINAÇÃO AMBIENTAL}

Resíduos de pesticidas, especialmente organoclorados (DDT e metabólitos, BHC, aldrin, heptacloro e outros), estão presentes nas áreas mais remotas da Terra. Podem ser transportados por grandes distâncias através do mundo, retidos no organismo de animais migrantes marinhos ${ }^{32,33}$, por correntes de ar e oceânicas ${ }^{12}$. Já foram detectados nos Andes chilenos, em altitudes elevadas ${ }^{34}$.
Pesquisadores especulam que os poluentes se movem pela atmosfera, a partir de suas fontes em locais quentes do globo, e se condensam ao atingirem regiões mais frias, precipitando-se sobre solos, vegetações e cursos de água, processo este conhecido por destilação global ${ }^{35,36}$. Isto pode ser a causa das altas concentrações de DDT e outros organoclorados encontradas nas regiões polares, após serem transportados por longas distâncias ${ }^{13}$.

Os padrões de distribuição do DDT e outras substâncias classificadas como poluentes orgânicas persistentes (POPs) ou contaminantes lipofílicos persistentes, sugerem que estas substâncias são transportadas através da atmosfera por longas distâncias. Uma comparação sistemática entre os hemisférios norte e sul indica que aquele encontra-se mais poluído. E o processo de equilíbrio entre ambos é relativamente lento. No entanto, os níveis de DDT, assim como o dos HCBs e PCBs (este último grupo não tem origem como pesticida, mas seus componentes possuem o mesmo comportamento ambiental, na condição de persistência e capacidade de se acumular em organismos vivos), encontram-se mais altos próximos às fontes devido à sua menor volatitlidade em comparação com os demais organoclorados ${ }^{13}$.

Os pesticidas aplicados em lavouras, terrenos ou em processos de reflorestamento ligam-se aos sedimentos do solo e sofrem ação de lixiviação e contaminação de águas, volatilização e contaminação do ar ou são absorvidos por microorganismos, vegetais ou animais ${ }^{37}$.

A contaminação pode alcançar águas subterrâneas ${ }^{38} \mathrm{e}$ águas tratadas para consumo humano ${ }^{39}$, embora nesses estudos estivesse em níveis considerados seguros.

Em geral, os lençóis freáticos apresentam riscos moderados de contaminação, porém as cargas contaminantes variam, dependendo de condições locais (temperatura, acidez, salinidade, etc) ${ }^{15}$. Avaliouse a carga contaminante, resultante de atividades agropecuárias no estado de São Paulo, e concluiu-se que os maiores riscos estão associados a locais onde há uso intensivo de herbicidas, principalmente em áreas de cultivo de cana-de-açúcar ${ }^{37}$.

Ao pesquisar a presença de DDT em solos e paredes de uma propriedade em Jacarepaguá, RJ, entre abril de 1997 e março de 1999 , Vieira et al..$^{40}$ verificou que os solos ainda apresentavam contaminação com DDT. A última aplicação pela Fundação Nacional de Saúde (FUNASA) fora em 1990, para controle de leishmaniose. Porém, os valores relativos aos solos, de 1999, reduziram-se em relação aos valores encontrados em 1997, tendo diminuído de $351 \mu \mathrm{g} /$

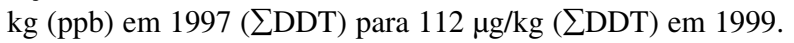

\section{CONTAMINAÇÃO DA BIOTA}

As propriedades físico-químicas e biológicas do DDT e seus metabólitos, e demais organoclorados, fazem com que estes compostos sejam rapidamente absorvidos pelos organismos. As taxas de acumulação variam entre as espécies, e de acordo com a concentração, as condições ambientais e o tempo de exposição.

Os organismos acumulam estes compostos a partir do meio circundante ou pelos alimentos. No meio aquático, a absorção a partir do meio é mais rápida, enquanto que para os animais terrestres, a alimentação, seja carnívora, herbívora ou detritívora, é a via princi$\mathrm{pal}^{15}$.

Diferentes organismos metabolizam o DDT por diferentes vias. Dos principais metabólitos, DDE é o mais persistente, embora nem todos os organismos o produzam a partir do $\mathrm{DDT}^{15}$.

Denomina-se bioconcentração a absorção do composto diretamente do meio abiótico, resultando em uma concentração do composto no organismo maior que no meio abiótico que o cerca ${ }^{41}$. A proporção entre a concentração do composto no organismo e a concentração externa consiste no fator de bioconcentração. Os fatores de bioconcentração para peixes são geralmente maiores que os de 
seres vivos invertebrados, em relação aos organoclorados ${ }^{15}$. Muitos destes constituem suas presas.

Bioacumulação é a absorção do composto pelo organismo do meio abiótico ou biótico, podendo ou não a concentração exceder a da fonte ${ }^{41}$. A maioria do DDT presente nos peixes é absorvida a partir do corpo dos organismos que eles consomem. A maioria do DDT e metabólitos são retidos (bioacumulados) nos tecidos ricos em lipídios ${ }^{42,43}$.

A posição do organismo na cadeia biológica tem importante influência sobre se a substância apresenta elevada absorção e baixa eliminação. A isto chama-se biomagnificação, onde a concentração do composto aumenta ao longo da cadeia alimentar. Ocorre biomagnificação quando as concentrações de um poluente nos tecidos de um organismo excedem as concentrações do nível trófico adjacente inferior em mais de $100 \%$. É bem conhecida, por exemplo, a biomagnificação de metilmercúrio em ecossistemas aquáticos ${ }^{44}$.

Em geral, seres vivos situados nos níveis tróficos mais altos tendem a conter mais organoclorados no organismo ${ }^{15}$, mas isso não é uma regra, podendo ser grandemente influenciada pelos hábitos alimentares, como por exemplo, em peixes detritívoros ou iliófagos, como o curimba (Prochilodus lineatus) que se alimentam de matéria orgânica em decomposição depositada no fundo ${ }^{42}$.

A biomagnificação do DDT foi demonstrada no Zimbabwe por Berg et al. ${ }^{45}$, em uma área endêmica da doença do sono, transmitida pelas moscas tsé-tsé, e malária, transmitida por mosquitos, onde estes vetores eram combatidos com o uso do DDT. As concentrações de $\sum$ DDT encontravam-se elevadas nos peixes carnívoros da represa do Lago Kariba (até $0,08 \mathrm{mg} / \mathrm{kg}$, ou ppm) e na aves (0,09 ppm). Embora estes níveis estivessem abaixo da concentração considerada perigosa para seres humanos, os autores sugeriram que podem ocorrer diversos efeitos no meio ambiente, como diminuição da população das aves e de peixes predadores, causando um desequilíbrio no ecossistema.

Ruus et al. ${ }^{46}$, em estudo sobre biomagnificação de cinco grupos distintos de organoclorados (PCBs, ¿DDT, clordanos, HCHs e HCB), em uma cadeia alimentar de um fiorde no norte norueguês, que envolvia os peixes Ammodytes marinus e Gadus morhua (bacalhau), e as focas Phoca vitulina e Halichoerus grypus, verificaram que o maior fator de biomagnificação encontrado foi o do $\sum$ DDT $(36,9)$, da Phoca vitulina para o Ammodytes marinus. As concentrações dos poluentes geralmente aumentaram de acordo com o nível trófico. Os padrões de composição dos organoclorados também diferiam entre as espécies; dentre os compostos de $\Sigma \mathrm{DDT}$, as proporções de $p, p^{\prime}-\mathrm{DDE}$ aumentaram de acordo com o maior nível trófico, enquanto que os de DDD decresceram. Segundo os autores, os dados sugeriram que os mecanismos de bioacumulação nos níveis tróficos mais baixos dependem principalmente de fatores físico-químicos, como a solubilidade dos poluentes, enquanto que nos superiores, são afetados por fatores bioquímicos, como o metabolismo corporal.

\section{CONTAMINAÇÃO DE ECOSSISTEMAS AQUÁTICOS, MARINHOS E DE ÁGUA DOCE}

Análise de amostras de água, partículas e suspensão e sedimentos de fundo, coletadas na Baía de Daya, China ${ }^{47}$, indicou contaminação por organoclorados. Os perfis de distribuição destes poluentes sugerem que há várias fontes contribuindo para a contaminação da baía, incluindo lixiviação de solos, descarga de águas contaminadas por lixo e esgoto e detritos de indústria naval. A faixa de DDT foi de 26,8 a 975,9 ng/L na água e de 0,14 a 20,27 ng/g (peso seco) nos sedimentos. E a proporção DDT/DDE + DDD indica fontes recentes, o que aponta para a necessidade se tomar medidas urgentes para deter o uso de pesticidas como DDT e lindano.
Também na China, foram analisadas amostras de sedimentos de três estuários da costa sudeste, para a presença de hidrocarbonetos aromáticos policíclicos, PCB e pesticidas organoclorados ${ }^{48}$. As altas concentrações de $\sum$ DDT (2,5-24,7 ng/g) encontradas devem-se ao uso indiscriminado de DDT, o que se sabe ter ocorridos nos anos 60 e 70, contaminando os estuários consideravelmente, a partir de rios e lixiviação de solos. Atualmente, as altas proporções DDT/DDD e DDT/DDE indicam lenta degradação, adição recente de DDT ou fatores ambientais excepcionais. A predominância de DDD sobre DDE em dois dos estuários implica em degradação em condições anaeróbicas, devido à baixa taxa de circulação de água para o mar aberto. No estuário onde havia mais intercâmbio com a água do mar, o DDE predominava sobre o DDD. As concentrações dos outros inseticidas e PCBs estavam baixas.

Em um monitoramento de ecossistema marinho de águas profundas, determinou-se a presença de organoclorados em peixes e outros organismos da Baía de Suruga, Japão, e comparou-os com espécimes coletadas de águas rasas, na mesma baía. Congêneres de PCB foram os predominantes, seguidos de congêneres de DDT. Não houve diferença significativa em relação às concentrações presentes nos organismos de águas rasas, exceto para $\mathrm{HCH}$, onde foram maiores. Também não foi verificada correlação com a cadeia alimentar, sendo as concentrações atribuíveis a uma partição de equilíbrio com a fração de lipídios corporais. Em todos os organismos, o composto de $\sum$ DDT predominante foi o DDE, exceto em uma espécie de lagosta. Por último, os autores declaram que os níveis encontrados foram menores que os verificados por outros autores, em outros oceanos e mares do mundo 32 .

Nas regiões tropicais, radiação solar e altas temperaturas podem influenciar favoravelmente na remoção dos organoclorados do ambiente, ao gerar volatilização e degradação. Foi o que sugeriu o estudo empreendido por Kumblad et $a l .{ }^{49}$ no lago Songkhla, Tailândia, ao determinar as concentrações de DDDT em quatro espécies de peixes. A alta produtividade biológica também contribuiu para as baixas concentrações encontradas, por resultar em um efeito diluente, ao distribuir pela grande quantidade de matéria orgânica presente. A magnitude de $\Sigma$ DDT nos peixes foi similar às concentrações encontradas em estudos anteriores, citados no texto, em outras partes da Tailândia, e inferior ao que se verificara anteriormente no Mar Báltico, localizado no norte da Europa ${ }^{50}$.

O trabalho de Kumblad et al. $^{49}$ fornece dados para um melhor entendimento do comportamento do DDT em ecossistemas aquáticos tropicais. As baixas concentrações de LDDT encontradas nos peixes do lago acima devem-se à diluição biótica e processos de degradação. Isto demonstra a necessidade de novos estudos sobre o comportamento do DDT e outros organoclorados nos trópicos, a fim de se compreender melhor sua distribuição global.

Trabalho similar já havia sido feito em $1990^{45}$, em peixes da represa do Lago Kariba, fronteira de Zimbabwe com Zâmbia. Os níveis encontrados eram similares aos vistos em peixes da Suécia e outros locais de clima temperado, onde o DDT fora proibido há mais tempo. Os autores postularam que isso era devido a degradações biológica e química, radiação ultra-violeta e temperatura.

Torres $^{51}$ pesquisou a presença de DDT e metabólitos, bem como outros pesticidas organoclorados, bifenilas policloradas (PCBs) e hidrocarbonetos aromáticos policíclicos, nos sedimentos dos rios brasileiros Guandú e Paraíba do Sul, Rio de Janeiro, e Rio Rato, afluente do Rio Tapajós, estado do Pará. Os dois primeiros situam-se em locais de poluição de origem industrial ou zonas agrícolas, enquanto que o Rio Rato situa-se em local endêmico para malária e febre amarela, que são combatidas com o uso de inseticidas. A presença de 0,2 a 0,8 ppb de DDT em sedimentos de fundo pode estar relacionada ao uso agrícola nos rios Guandú e Paraíba do Sul. No caso do Rio Rato, onde o 
DDT fora aspergido dentro de casas, encontrou-se até 68 ppb nos sedimentos. No solo, os níveis ultrapassavam 1 ppm.

Nas regiões polares, a degradação dos organoclorados da biosfera é ainda mais baixa que nos trópicos, o que faz com que sua remoção seja ainda menor, e a bioacumulação e a biomagnificação continuam ocorrendo. Strachan et al..$^{52}$ participaram da expedição russo-americana aos mares de Bering e Chukchi, organizada pelo Instituto Russo de Clima e Ecologia Global e pelo US Fish and Wildlife Service, em agosto-setembro de 1993. As coletas de amostras de águas foram realizadas em 21 pontos distintos e pesquisadas quanto à presença de 19 pesticidas organoclorados, 11 clorobenzenos e 113 congêneres de PCB.

A maioria dos organoclorados foi encontrada em maior concentração na coluna d'água que nos sedimentos em suspensão, sendo $\alpha$ $\mathrm{HCH}$ e $\gamma-\mathrm{HCH}$ os encontrados em maior quantidade. Todas as amostras tiveram $p, p^{\prime}-D D T$ como principal resíduo de $\Sigma$ DDT. Isto indica uso recente, embora não necessariamente na região estudada. Os níveis decresciam no sentido sul-norte.

Uma pesquisa foi realizada no Canadá, em amostras de água coletadas mensalmente no Rio São Lourenço e quatro de seus estuários, de agosto de 1990 a novembro de $1991^{53}$. As análises de determinação de $\Sigma$ DDT, indicaram que as maiores concentrações ocorreram no mês de abril, durante o degelo de primavera (média de 3,02 ng/L), e decresceram logo em seguida. Segundo os autores, as duas fontes mais prováveis, para o Rio São Lourenço, são, a absorção do $\sum$ DDT atmosférico, carreado pela neve, e a água contaminada proveniente dos Grandes Lagos. Nos tributários, o aumento da concentração em abril é atribuída ao derretimento da neve e à lixiviação dos solos contaminados. Também foi verificado, nas águas dos tributários, que as razões DDT/DDE + DDD diminuem no período de abril a setembro, indicando um ciclo anual tempo/temperatura dependente sobre as concentrações ambientais. Esta tendência não ocorreu no Rio São Lourenço, sendo atribuído a um uso então recente de Dicofol, inseticida que contém resíduos de DDT como impureza, mantendo, com isso, as razões DDT/DDE + DDD constantes.

A queda de neve carreia contaminantes orgânicos da atmosfera e os concentra rente ao solo, ao formar as calotas de neve. Durante o degelo, os contaminantes podem alcançar os ambientes aquático e terrestre, ou se volatilizarem e retornarem à atmosfera. Wania ${ }^{54}$ apresentou um esquema para descrever este processo, com cálculos de natureza físico-química, com DDT e outros organoclorados. Concluiu que o DDT, diferente dos demais, tende a ser retido no solo pela matéria orgânica, até ser carreado por ação mecânica de lixiviação.

Em um estudo sobre interação entre eutrofização e contaminantes, Gunnarsson et al..$^{55}$ citam que contaminantes bioacumulativos, como organoclorados se diluem onde há uma grande biomassa, ou grande quantidade de matéria orgânica presente, o que ocorre nos ambientes aquáticos eutrofizados.

Mas, segundo Bignert et al..$^{50}$, o decréscimo das concentrações de organoclorados em ecossistemas de águas doce e marinha da Suécia, constatado num monitoramento de 28 anos (1967-1995), o principal fator para a redução dos níveis deveu-se, provavelmente, às medidas governamentais que foram tomadas para reduzir a poluição. Os decréscimos nas concentrações ocorreram similarmente em todos os ambientes, mesmo nos lagos mais remotos, não eutrofizados, e situados longe de fontes poluentes. Além disso, houve diferenças marcantes no tempo de depuração dos outros organoclorados, como $\mathrm{HCH}$ e PCB. Os autores ainda apontam um súbito aumento, seguido de uma súbita redução, da concentração no período 1983-1986, após uma campanha de controle de insetos ter sido realizada na antiga Alemanha Oriental, por meio de DDT.

As variações nas concentrações de organoclorados em peixes de lagos de regiões árticas, que são contaminadas somente por trans- porte atmosférico por longas distâncias até serem lá depositados, podem ser devidas a concentrações variáveis, presentes na precipitação, ar, água e sedimentos. Estes fatores, por sua vez, variam com a localização geográfica e as características da água do lago ou cursos de água que o alimentam. Em um estudo realizado em um lago remoto, não eutrofizado, no norte canadense ${ }^{56}$, foram determinados os níveis de organoclorados presentes na água, sedimentos e biota, para examinar a participação da atmosfera na deposição de organoclorados e sua transferência de compartimentos abióticos para bióticos por bioacumulação. Os resultados sugerem que a absorção dos organoclorados presentes na atmosfera é uma rota muito importante, bem como a precipitação. Avaliações das trocas água - ar sugeriram que as águas do lago estavam próximas do equilíbrio com a atmosfera, para $p, p$ '- DDE, $\alpha-\mathrm{HCH}$ e trans-nonaclor. Em relação à cadeia alimentar, houve correlação com o nível trófico de cada um, bem como com a quantidade lipídica de cada ser vivo.

\section{DDT e organoclorados em peixes}

A biota aquática é um importante reservatório de DDT, metabólitos e outros organoclorados no ambiente, porque está bem documentado o processo de biomagnificação através da cadeia alimentar, apresentando as maiores concentrações nos organismos de nível trófico mais elevado, como os peixes carnívoros. Assim, além dos efeitos tóxicos dos pesticidas organoclorados para a exposição humana, a possibilidade das espécies de níveis tróficos elevados serem afetados pode acarretar desequilíbrio na estrutura das comunidades ${ }^{15}$. Ainda há os peixes que não estão em níveis tróficos superiores, mas que poderão atingir altos níveis de contaminação, ao absorverem nutrientes que possuirem grande carga de poluentes, por estes se associarem aos sedimentos de fundo ${ }^{42,17}$.

Bressa et al. ${ }^{17}$ estudaram os níveis de compostos organoclorados e SDDT em enguias (Anguilla anguilla, L.) oriundos do delta do Rio Pó, Itália. Esta espécie possui um considerável conteúdo de tecido adiposo, o que predispõe ao acúmulo destes contaminantes, além de ter como hábito alimentar, a ingestão de matéria orgânica em decomposição que está em contato com os sedimentos do fundo (detritívora). As capturas foram feitas em março (primavera) e outubro (outono). Os principais compostos identificados foram PCBs, HCB, $p, p$ '- DDT e seus metabólitos $p, p$ '- DDE e $p, p$ '- DDD. As concentrações foram maiores nos peixes capturados na primavera, $\mathrm{e}$ se correlacionaram com a concentração de gordura presente.

Ainda segundo Bressa et al. ${ }^{17}$, o metabólito de DDT mais abundante foi o $p, p$ '-DDE, que chegou a uma concentração máxima de $36,45 \mu \mathrm{g} / \mathrm{kg}$ (ppb) de peso seco, com média de 29,65 $\pm 6,80 \mathrm{ppb}$. As concentrações de $p, p$ '- DDT e $p, p$ '- DDD foram, respectivamente, $4,48 \pm 0,45$ e 21,42 $\pm 5,66$, nas amostras coletadas na primavera. Os autores concluíram que não havia risco para a saúde pública, pois os níveis de organoclorados detectados estavam em níveis abaixo de serem considerados perigosos, que é de $2000 \mathrm{ng} / \mathrm{g}$ ( $2 \mathrm{ppm}$ ), segundo a U.S. Food and Drug Administration (USFDA) (apud Bressa et al. $)^{17}$, mas poderia ser perigoso para os animais predadores, como aves, $\mathrm{o}$ que configuraria um risco ambiental.

A fim de avaliar a exposição das populações ribeirinhas, Viganò et al. ${ }^{57}$ pesquisaram níveis de PCBs, DDTs ( $p, p^{\prime}$ - DDT + p,p'- DDE), e equivalentes de tetraclorodibenzeno-para-dioxinas (TCDD) em sedimentos do fundo e em três espécies de peixes ciprinídeos dos rio Pó, Itália, tendo como referência para os dois pontos de coleta a confluência de outro rio, Rio Lambro. As duas espécies carnívoras revelaram-se as mais contaminadas, e uma delas (Leuciscus cephalus) mostrou nível de contaminação superior, em mais de 2 vezes, em relação ao ponto de coleta situado abaixo da confluência do rio Lambro. Esta área do rio está exposta a uma complexa mistura de 
poluentes químicos industriais e de atividades agrícolas, situadas nas margens de ambos os rios, apresentando uma contaminação que influenciou os níveis de poluição dos pontos de coleta. A concentração média de DDT encontrada nas 3 espécies (Chondrostoma söeta, Leuciscus cephalus e Barbus plebejus) foi, respectivamente, 871, 856 e $2.204 \mathrm{ppb}$ (ou ng por grama de peso de tecido adiposo), acima da confluência do rio Lambro, e 1.137, 2.296 e 4.029 ppb abaixo da confluência. Verificou-se a influência, tanto da posição na cadeia alimentar, quanto da quantidade de poluentes, na concentração destas substâncias retidas nos organismos. Neste caso, os níveis de organoclorados detectados estavam em níveis superiores aos considerados perigosos, que é de $2000 \mathrm{ng} / \mathrm{g}$ ( 2 ppm) (U.S. Food and Drug Administration [USFDA] apud Bressa et al. ${ }^{17}$ ).

$\mathrm{Na}$ Argentina, Menone et $a .^{2}$ analisaram as concentrações de PCBs e diversos pesticidas organoclorados, incluindo DDT e metabólitos, no organismo de peixes de água doce da espécie Odontesthes bonariensis, na lagoa de Mar Chiquita. Os compostos foram detectados em concentrações na ordem de ng/g (ppb), com níveis em tecidos na ordem decrescente: tecido adiposo $>$ fígado $>$ gônadas $>$ gordura mesentérica $>$ músculos, refletindo a diferença no conteúdo de gordura. Os pesticidas predominantes foram DDT e metabólitos, lindano e ciclodienos, refletindo o uso passado e presente destes pesticidas na região. A proporção de pesticidas organoclorados para PCBs foi maior que 1 , sendo consistente com a contaminação da região por pesticidas. No entanto, as concentrações dos compostos estavam abaixo dos limites máximos toleráveis para consumo humano.

Lara et al ${ }^{58}$ detectaram isômeros de BHC e DDT e metabólitos, principalmente $p, p$ '- DDE, em peixes do litoral de Santos, SP. Em uma amostragem de 50 peixes, os isômeros de BHC foram detectados em $84 \%$ das amostras, variando de 10 a $940 \mu \mathrm{g} / \mathrm{kg}(\mathrm{ppb}) \mathrm{de}$ BHC total; e DDT e metabólitos ( $\sum$ DDT) foram detectados no organismo de três tainhas e uma salteira ( $8 \%$ das amostras), variando de 20 a $41 \mu \mathrm{g} / \mathrm{kg}$ (ppb).

Matsushita e Souza ${ }^{42}$ encontraram 8 tipos diferentes de organoclorados em três espécies de peixes no Rio Paraná, situado na divisa de estados PR/MS. Entre eles estavam p,p'- DDT e $p, p^{\prime}$ - DDE. Os autores mencionam a importância da quantidade de tecido adiposo, a posição na cadeia trófica e o hábito alimentar como determinantes da quantidade no organismo. Os autores citam trabalhos anteriores que haviam detectado os pesticidas nos vegetais que serviam de alimento para uma das espécies, e terminam o trabalho declarando que a contaminação dos peixes por estes resíduos organoclorados é preocupante, porque fazem parte da alimentação da população ribeirinha e são comercializados nos estados do Paraná, Santa Catarina, São Paulo e Mato Grosso do Sul.

\section{MONITORAMENTO DE DDT E OUTROS PESTICIDAS EM ÁGUAS SUPERFICIAIS}

O monitoramento de DDT e outros pesticidas em águas superficiais é pobre em várias partes do mundo, especialmente em países em desenvolvimento. Embora pesticidas estejam incluídos em vários programas governamentais, há falta de verba, e dificuldades de aplicá-los no exato momento do ano em que os pesticidas são utilizados, na agricultura ou em programas de saúde, por exemplo. Além disso, países subdesenvolvidos têm dificuldade de realizar as análises, devido a problemas de falta de profissionais, reagentes e técnicas adequadas. Novas técnicas utilizando procedimentos de imunoensaios, para detectar presença de pesticidas, poderiam reduzir os custos e aumentar a eficiência ${ }^{59}$.

Existem problemas que podem influenciar nas análises de água, como a presença de sólidos em suspensão. Suas concentrações na água de rios podem variar de 10 a $10000 \mathrm{mg} / \mathrm{L}$, e serem ainda maiores em certas ocasiões, como lixiviação em época de chuvas fortes. Segundo Ongley et al. ${ }^{60}, 67 \%$ do DDT é transportado em associação com a matéria em suspensão, quando a concentração dos sólidos em suspensão está em torno de $100 \mathrm{mg} / \mathrm{L}$, e aumenta para $93 \%$ quando sobe para $1000 \mathrm{mg} / \mathrm{L}$. E foi detectada em $100 \%$ quando a concentração está em 10000 mg/L.

Segundo a FAO/ASFA ${ }^{59}$, problemas analíticos como quantidades abaixo do limite de detecção, controle de qualidade deficiente e análises de recuperação que podem variar de 50 a $150 \%$, para compostos orgânicos, significa que os dados de monitoramento podem ser indicadores deficientes de poluição por pesticidas, quando estes estão adsorvidos aos sólidos em suspensão. Considera-se que o valor denominado "Não detectável" pode ser devido a procedimentos inadequados de amostragem e/ou análise. Considera-se que valores associados a sedimentos sejam, em geral, muito maiores que os registrados, e que valores ditos "Não detectáveis" podem não corresponder à realidade ${ }^{59}$

Claramente, isto causa dificuldades na avaliação de pesticidas em várias partes do mundo. Algumas agências de controle de água usam vários tipos de amostras (água + sedimento + biota), a fim de obter resultados mais acurados ${ }^{59}$.

Não obstante técnicas analíticas adequadas de água e/ou sedimentos, a presença de um pesticida persistente como o DDT não é fácil de interpretar. Sua presença pode tanto indicar que foi despejado recentemente no local, ou transportado por longas distâncias pela atmosfera, ou é um resíduo remanescente de seu uso em uma época passada. Por exemplo, DDT é encontrado frequentemente no território dos EUA, apesar de seu uso ter sido abolido há vários anos.

\section{CONTAMINAÇÃO DOS ALIMENTOS}

O DDT já era contra-indicado no tratamento de ectoparasitos do gado leiteiro, antes de ser proibido, porque é eliminado pelo leite, além de armazenar-se no tecido adiposo. A ocorrência de níveis tóxicos na carne e no leite concorreu para a proibição de sua fabricação e comercialização ${ }^{4}$.

Já foi registrada contaminação por DDT e outros organoclorados na América Latina em carne bovina, carne de aves, leite, frutas, hortaliças, legumes, cacau, arroz e até mesmo em óleos, de milho, soja, girassol e oliva. No caso dos produtos de origem vegetal, este pode ser contaminado tanto por absorção foliar após aspersão, quanto por translocação através do solo ${ }^{3}$.

Estimou-se que cerca de $90 \%$ do DDT e metabólitos retidos no organismo dos seres humanos é proveniente da alimentação. Em 1965, quando ainda não era proibido, a absorção pelos cidadãos americanos era de aproximadamente $0,04 \mathrm{mg} /$ dia dos alimentos, e de $4,6 \mathrm{x}$ $10^{-5} \mathrm{mg} /$ dia da água, de menos de $6,0 \times 10^{-5}$ do ar urbano e de menos de 5,0 x $10^{-4}$ do ar em regiões agrícolas, com uso constante do DDT ${ }^{61}$. Outros investigadores ${ }^{62,63}$ chegaram à mesma conclusão: a de que a ingestão de alimentos é a principal fonte de exposição ao DDT e outros compostos organoclorados para a maioria da população.

Analisando 44 amostras de leite comercializado na cidade de São Paulo, coletadas de fevereiro a dezembro de 1979, para determinação de pesticidas organoclorados, Lara et al. ${ }^{64}$ encontraram $p, p^{\prime}$ DDE em 95,4 \% das amostras, sendo que em apenas 15,9\% das amostras havia $p, p^{\prime}-$ DDT e $o, p^{\prime}$ - DDT. A média foi de $0,03(\mathrm{mg} / \mathrm{kg}$ de gordura do leite) ppm, com um máximo de 0,21 ppm.

Os mesmos autores fizeram trabalho semelhante entre $1980 \mathrm{e}$ 1981, desta vez com três marcas comerciais de leite tipo B, em 36 amostras em 1980 e 12 amostras em 1981. Esses valores variaram de 0 a $0,22 \mathrm{mg} / \mathrm{kg}$ em 1980 e de 0 a $0,10 \mathrm{mg} / \mathrm{kg}$ em 1981. Desta vez revelou-se um novo contaminante ambiental: o dieldrin, que é utili- 
zado como inseticida, e é também um metabólito do aldrin. Este variou de 0 a $0,04 \mathrm{mg} / \mathrm{kg}$ (gordura de leite) em ambos os anos ${ }^{65}$.

Baseados em estudos toxicológicos e epidemiológicos, Mariën e Laflamme ${ }^{66}$ recomendam uma concentração máxima de ingestão diária tolerável de DDT, para proteção à saúde de populações especialmente sensíveis (ex: neonatos e lactentes), de $0,005 \mathrm{mg} / \mathrm{kg} / \mathrm{dia}$. Neste mesmo trabalho, os autores concluíram, que as mães que se alimentavam regularmente de duas espécies de peixes do rio Yakima, estado de Washington - EUA, tinham concentrações de DDT no leite suficientemente altas $(2,4 \mathrm{mg} / \mathrm{kg})$ para exporem seus filhos a dosagens de DDT acima da ingestão diária aceitável. A ingestão pelos filhos lactentes foi calculada em $0,02 \mathrm{mg} / \mathrm{kg}$ dia. As concentrações médias nos peixes eram de $0,84 \mathrm{mg} / \mathrm{kg}$ e $1,63 \mathrm{mg} / \mathrm{kg}$.

De acordo com Vieira ${ }^{40}$, a concentração média de $\sum$ DDT encontrado em ovos de galinha apresentou-se em torno de $1,98 \mathrm{mg} / \mathrm{kg}$ (ppm) de lipídios extraíveis, na gema, sendo $82 \%$ de $p, p$ '-DDE e $16 \%$ de $p, p$ '-DDT.

Segundo a Comissão do Codex Alimentarius ${ }^{21}$, os limites máximos permitidos (tolerados) são $0,05 \mathrm{mg} / \mathrm{kg}$ para o leite, $0,1 \mathrm{mg} / \mathrm{kg}$ para grãos, $5,0 \mathrm{mg} / \mathrm{kg}$ para carnes e $0,5 \mathrm{mg} / \mathrm{kg}$ para ovos. A USFDA recomenda um máximo de 2,0 mg/kg para peixes (apud Bressa et al. ${ }^{17}$ ).

Kalantzi et al. ${ }^{67}$ usaram a manteiga como indicador para refletir as escalas global e regional de PCBs e outros organoclorados (entre eles o DDT) no ar. Isto foi baseado no fato de que estes poluentes se concentram na gordura do leite bovino, onde as concentrações estão relacionadas pela ingestão de pastos ou silagens, que por sua vez sofrem a ação da deposição atmosférica. As concentrações de $\Sigma$ DDT e HCH nas amostras variaram em várias ordens de magnitude, com os maiores níveis sendo encontrados em áreas de uso comum, como Índia e zonas específicas das Américas do Sul e Central. Os autores consideraram a manteiga como um indicador eficaz, mas ainda faltam dados quanto a fatores climáticos e de manejo do gado, que influenciam o processo de transferência ar-pasto/silagem-gordura do leite.

\section{DDT E CONTROLE DE MALÁRIA}

Um dos mais importantes usos do DDT é o controle de mosquitos vetores da malária, cuja principal espécie transmissora, Anopheles darlingi, já foi encontrada do México até o norte da Argentina. No Brasil, antes das campanhas de erradicação, somente os estados de Paraíba, Rio Grande do Norte, Santa Catarina e Rio Grande do Sul estavam livres. Ocorre em locais com grandes volumes de água, como represas, lagos e grandes rios, límpidos e pobres de matéria orgânica ou sais ${ }^{7}$.

O principal recurso disponível para interromper a transmissão da malária consiste na aplicação de inseticidas de ação residual, com aplicação intradomiciliária. O êxito desta operação está no fato de agirem no local onde se dará a transmissão mosquito - ser humano. Recomendam-se concentrações que assegurem mortalidade de 65 a $85 \%$ dos insetos.

Os inseticidas usados são, na ordem de preferência, hidrocarbonetos clorados, organofosforados, carbamatos e piretróides sintéticos (Tabela 1).

Tabela 1. Concentração e duração dos efeitos dos principais inseticidas utilizados no controle da malária ${ }^{7}$

\begin{tabular}{ccc}
\hline Inseticidas & $\begin{array}{c}\text { Taxa de aplicação } \\
\left(\mathrm{g} / \mathrm{m}^{2}\right)\end{array}$ & $\begin{array}{c}\text { Duração do efeito } \\
(\text { meses })\end{array}$ \\
\hline DDT & 1 ou 2 & 6 a 12 \\
dieldrin & 0,5 & 6 a 12 \\
lindano & 0,5 & 3 \\
\hline
\end{tabular}

Em pesquisa para controle global de malária, um grupo de estudo da Organização Mundial de Saúde promoveu debate sobre a proibição ou não de DDT, com base na possível associação entre DDT e câncer humano, bem como de DDT no leite materno. O comitê chegou às seguintes conclusões ${ }^{22}$ :

1. que não há provas suficientes de efeitos nocivos à saúde humana pela exposição ao DDT, após aplicação em interiores domiciliares;

2. não haveria, portanto, justificativa de ordem toxicológica ou epidemiológica para modificar a política atual de aspersão de DDT em interiores de residências;

3. foram especificadas as condições a serem aplicadas em campanhas de saúde contra a malária;

4. ao planejar um programa de controle de malária em um país ou região, serão levados em conta os seguintes fatores:

- o custo de cada inseticida;

- a disponibilidade de outros métodos de luta antivetorial, onde se incluem os inseticidas alternativos, levando-se em conta os custos e riscos à saúde humana de cada um;

- o surgimento de insetos resistentes, em especial a resistência cruzada, que não é impossível e pode surgir quando se utilizam os inseticidas alternativos;

- a aceitação da população ante o emprego de novos, sobretudo em relação à saúde pública.

Tendo em conta a escassez de dados que indiquem os efeitos nocivos causados pela aplicação no interior das residências, devem ser feitas investigações epidemiológicas que comprovem os fatos, mediante procedimentos científicos rigorosos.

Também devem ser executados estudos adicionais para:

a) examinar as consequências à saúde dos lactentes que seriam causadas pela ingestão de DDT pelo leite materno;

b) investigar a fundo qualquer associação presumida entre o emprego de DDT, em metas de controle antipalúdicas, e o aumento da incidência de câncer.

Os anofelinos adquiriram resistência aos pesticidas, entre eles, os organoclorados. Isso explicaria porque os casos de malária voltaram a crescer durante os anos $70^{7}$.

O controle sistemático de combate aos vetores da doença iniciouse na Amazônia, em 1945, nas localidades de Breves e Santa Mônica, Pará. Em setembro de 1947 já havia sido utilizado em outras localidades do estado, no estado do Amazonas e em Guaporé (atual Rondônia) e Amapá, territórios federais na época ${ }^{68}$. Segundo Roberts ${ }^{5}$, o reaparecimento da malária na América do Sul deve-se ao fato de os países terem deixados de utilizar DDT nos programas de controle. Os dois únicos países onde a malária não reapareceu foram Venezuela e Equador, devido ao fato de o DDT não ter sido proibido.

Alguns malariologistas argumentam que a aplicação dentro de residências, que seria prejudicial à saúde humana, não é convincente. E que em vários países, o uso de inseticidas organoclorados é o único meio economicamente viável de controle, assim como para a leishmaniose. Seus escassos orçamentos para as campanhas de saúde não possibilitariam substituir satisfatoriamente os inseticidas organoclorados, tendo em vista os preços mais elevados de possíveis alternativas ${ }^{69}$.

Os custos mais elevados de controle por meio de outros pesticidas superariam os eventuais riscos à saúde, se houver. Os autores argumentam que são inconsistentes os indícios de malefícios à saúde causados por DDT e organoclorados, bem como que a aplicação dentro das casas não causa riscos ao meio ambiente ${ }^{69}$.

Durante a Conferência das Nações Unidas, realizada entre 4 e 10 de dezembro de 2000, ficou declarado que oito pesticidas considerados nocivos ao ambiente e à saúde serão proscritos pelos países signatários, a saber: hexaclorobenzeno, endrin, dodecacloro, toxafeno, 
clordano, heptaclor, aldrin e dieldrin. Mas propôs-se que o DDT ainda seja utilizado no controle de malária, pois países que o utilizam para este propósito, ainda necessitam de recursos e tempo para definir e implementar alternativas. O DDT será utilizado somente dentro do interior de residências, e não mais para a agricultura ${ }^{70}$.

\section{AGRADECIMENTOS}

Esse trabalho teve o apoio da CAPES (bolsa de doutorado: MSc. C. D'Amato) e do CNPq (PRONEX 0877). O laboratório cromatográfico foi construido durante a cooperação internacional $C^{*} 11$ CT93-0055 (Comunidade Européia). O Dr. J. Torres é 'Selikoff Fellow' da Mount Sinai School of Medicine (Grant 1 D43 TW00640 - Fogarty International Center of the National Institutes of Health).

\section{REFERÊNCIAS}

1. Klaasen, C. D. Em As Bases Farmacológicas da Terapêutica; Gilman, A. G.; Goodman, L. S.; Rall, T. W.; Murad, F., eds.; Guanabara Koogan: Rio de Janeiro, 1985, cap. 70.

2. Menone, M. L.; De Moreno, J. E. A.; Moreno, V. J.; Lanfranchi, A. L.; Metcalfe L.; Metcalfe, C. D.; Arch. Environ. Contam. Toxicol. 2000, 18, 202.

3. OMS (Organisation Mondiale De La Santé); Critères d'Hygiene de l'Environment: DDT et ses Derivés. Grande Bretagne, 1982, vol. 9.

4. Pardi, M. C., Santos, I. F. dos; de Souza, E. R.; Pardi, H. S.; Ciência, Higiene e Tecnologia da Carne, EDUFF-UFG: Goiânia, 1993.

5. Roberts, D. R.; Pestic. Safety 1999, 2, 4.

6. Oliveira Filho, A. M.; Proceedings of the International Workshop on Organic Micropollutants in the Environment, Rio de Janeiro, Brasil, 1997.

7. Rey, L.; Parasitologia, $2^{\mathrm{a}}$ ed., Guanabara Koogan: Rio de Janeiro, 1991.

8. Carson, R.; Silent Spring, Hougthon Mifflin Company: New York, 1962.

9. Brasil. Ministério da Agricultura. Portaria n ${ }^{\circ} 356$, Diár. Of. União, Brasília, 15 out. 1971 , Seç. 1. p. 8318.

10. Brasil. Ministério da Agricultura. Portaria n ${ }^{\circ}$ 357. Diár. Of. União, Brasília, 15 out. 1971 , Seç. 1, p. 8318.

11. Brasil. Ministério da Agricultura. Portaria n 329. Diár. Of.União, 3 set 1985, Brasília, Seç. 1, p. 12941.

12. OMS (Organisacion Mondial de la Salud); Serie de Informes Tecnicos: Lucha Antivectorial Aplicada al Paludismo y a Otras Enfermedades Transmitidas por Mosquitos, 1995.

13. Connell, D. W.; Miller, G. J.; Mortimer, M. R.; Shaw, G. R.; Anderson, S. M.; Crit. Rev. Environ. Sci. Technol. 1999, 29, 47.

14. The Merck Index: An Encyclopedia of Chemicals, Drugs and Biologicals, $20^{\text {th }}$ ed., Merck \& CO. Inc: Whitehouse Station, 1996.

15. WHO (World Health Organization); Environmental Health Criteria: DDT and its Derivatives - Environmental Aspects, Finland, 1989, vol. 83.

16. Morrinson, R. D.; Newell, A. E.; Journal of Soil Contaminants 1999, 8, 63.

17. Bressa, G.; Sisti, E.; Cima, F.; Mar. Chem. 1997, 58, 261.

18. Brasil. Ministério da Saúde. Secretaria de Vigilância Sanitária. Departamento Técnico- Normativo. Divisão de Meio Ambiente e Ecologia Humana. Organização Pan- Americana de Saúde: Manual de Vigilância da Saúde de Populações Expostas a Agrotóxicos, Brasília,1997.

19. Zambrone, F. A. D.; Ciência Hoje 1986. 4, 44.

20. Paumgartten, F. J. R.; Proceedings of the International Workshop on Organic Micropollutants in the Environment, Rio de Janeiro: Brasil, 1997.

21. De Robertis, E. D. P.; De Robertis, E. M. F.; Bases da Biologia Celular e Molecular, $2^{\text {a }}$ ed., Guanabara Koogan: Rio de Janeiro, 1993.

22. Cocco, P.; Kazerouni, N.; Zahm, S. H.; Environ. Health Perspectives 2000 , $108,1$.

23. Vannuchi, M. T. O.; Dissertação de Mestrado, Universidade Estadual de Londrina, Brasil, 1988.

24. FAO/WHO; Codex Alimentarius Comission: Codex Alimentarius, $2 B$. Pesticide residues in foods-Maximum residue limits, Rome, 1996, cap. 2.

25. Beretta, M.; Dick, T.; Bull. Environ. Contam. Toxicol. 1994, 53, 357.

26. Bryan, T. E.; Gildersleeve, R. P.; Wiard, R. P.; Teratology 1989, 396, 525.

27. Lundholm, C. E.; Arch. Toxicol. 1991, 65, 220.

28. Kelce, W. R.; Stone, C. R.; Laws, S. C.; Earl, G. L.; Kemppalnen, J.A.; Wilson, E. M.; Nature 1995, 375, 581.

29. Hayes, T. B.; Wu, T. H.; Gill, T. N.; Environ. Toxicol. Chem. 1997, 16, 1948.
30. Beard, J.; Marshall, S.; Jong, K.; Newton, R.; Triplett-Mcbride, T.; Humphries, B.; Bronks, R.; Arch. Environ. Health 2000, 55, 177.

31. Romieu, I.; Hernandez-Avilla, M.; Lazcano-Ponce, E.; Weber, J. P.; Dewailly, E.; Am. J. Epidemiology 2000, 152, 363.

32. Lee, J. S.; Tanabe, S.; Takemoto, N.; Kubodera, T.; Mar. Pollut. Bull. 1997, 34, 250.

33. Marsili, L.; Casini, C.;.Marini, L.; Regoli, A.; Focardi, S.; Mar. Ecology Progress Series 1997, 273.

34. Ciudad, B. C.; Moyano, A. S.; Agricultura Técnica 1988, 48, 142.

35. Wania, F.; Mackay, D.; Ambio 1993, 22, 10.

36. Simonich, S. L.; Hites, R. A.; Science 1995, 269, 1851.

37. Rodrigues, G. S. Em LIBRO VERDE - Elementos para una politica agroambiental en el Cono Sur. Programa cooperativo para el desarrollo Tecnologico Agropecuario del Cono Sur - PROCISUR- Subprograma Recursos Naturales y Sostenibilidad Agrícola; Instituto Interamericano de Cooperacion para la Agricultura, Montevideo: Uruguay, 1997.

38. Lara, W. H.; Barretto, H. H. C.; Revista do Instituto Adolfo Lutz 1972, 32, 69.

39. Cáceres, O.; Castellan, O. A. M.; Moraes, G.; Pereira, M.; Ciência e Cultura 1981, 33, 1622.

40. Vieira, E. D. R.; Dissertação de Mestrado, Universidade Federal do Rio de Janeiro, Brasil, 2000.

41. Leblanc, G. A.; Environ. Sci.Technol. 1995, 28, 154.

42. Matsushita, M.; de Souza, N. E.; Arquivos de Biologia e Tecnologia 1994, $37,637$.

43. Kidd, K. A.; Schindler, D. W.; Hesslein, R. H.; Muir, D. C. G.; Can. J. Fisheries Aquatic Sciences 1998, 55, 869.

44. Reinfelder, J. R.; Fisher, N. S.; Luoma, S. N.; Nichols, J. W.; Wang, W. X.; Sci. Total Environ. 1998, 219, 117.

45. Berg, H.; Kiibus, M.; Kautsky, N.; Ambio 1992, 21, 444.

46. Ruus, A.; Ugland, K. I.; Espeland, O.; Skaare, J. U.; Mar. Environ. Res. 1999, 48, 131 .

47. Zhou, J. L.; Maskaoui, K.; Qiu, Y. W.; Hong, H. S.; Wang, Z. D.; Environ. Pollut. 2001, 113, 373.

48. Yuan, D.; Yang, D.; Wade, T. L.; Qian, Y.; Environ. Pollut. 2001, 114, 101.

49. Kumblad, L.; Olsson, A.; Koutny, V.; Berg, H.; Environ. Pollut. 2001, 112, 193.

50. Bignert, A.; Olsson, M.; Persson, W.; Jensen, S.; Zakrisson, S.; Litzén, K.; Eriksson, U.; Haggberg, L.; Alsberg, T.; Environ. Pollut.. 1998, 99, 177.

51. Torres, J. P. M.; Tese de Doutorado, Universidade Federal do Rio de Janeiro, Brasil, 1998.

52. Strachan, W. M. J.; Burniston, D. A.; Williamson, M.; Bohdanowicz, H.; Mar. Pol. Bull. 2001, 43, 132.

53. Pham, T.; Lum, K.; Lemieux, C.; Sci. Total Environ. 1996, 179, 17.

54. Wania, F.; Chemosphere 1997, 35, 2345.

55. Gunnarson, J.; Broman, D.; Jonsson, P.; Olsson, M.; Rosenberg, R.; Ambio 1995, 24, 384

56. Kidd, K. A.; Hesslein, R. H.; Ross, B. J.; Koczanski, K.; Steohens, G. R.; Muir, D. C. G.; Environ. Pollut. 1998, 102, 91

57. Viganò, L.; Arillo, A.; Aurigi, S.; Corsi, I.; Focardi, S.; Arch. Environ. Contam. Toxicol. 2000, 38, 209.

58. Lara, W. H.; Barretto, H. H. C.; Inomata, O. N. K.; Revista do Instituto Adolfo Lutz 1980, 40, 29.

59. http://www.fao.org/docrep/w2598e/w2598e07.htm, acessada em Janeiro 2002.

60. Ongley, E.D.; Krishnappan, B.G.; Droppo, I.G.; Rao, S.S.; Maguire, R.J.; Hydrobiologia 1992, 235/236, 177.

61. Campbell, J. E.; Richardson, L. A.; Schaffer, M. L.; Arch. Environ. Health 1965, 10,831

62. Durham, W. F.; Armstrong, J. F.; Quinby, G. E.; Arch. Environ. Health 1965, 11,641 .

63. Morgan, D. P.; Roan, C. C.; Arch. Environ. Health 1970, 20, 452.

64. Lara, W. H.; Barretto, H. H. C.; Inomata, O. N. K.; Revista do Instituto Adolfo Lutz 1980, 40, 65.

65. Lara, W. H.; Barretto, H. H. C.; Inomata, O. N. K.; Revista do Instituto Adolfo Lutz 1985, 45, 43.

66. Mariën, K.; Laflamme, D. M.; Risk Analysis 1995, 15, 709.

67. Kalantzi, O. I.; Alcock, R. E.; Johnston, P. A.; Santillo, D.; Stringer, R. L.; Thomas, G. O.; Jones, K. C.; Environ. Sci. Technol. 2001, 35, 1013.

68. Deane, L. M.; Freire, E. P. S.; Tabosa, W.; Ledo, J.; Revista do Serviço Especial e Saúde Pública 1948, 1, 1121.

69. Curtis, C. F.; Lines, J. D.; Parasitology Today 2000, 16, 119

70. Kapp, C.; Lancet 2000, 356, 2076. 